\title{
Trichotillomania: a case report with clinical and dermatoscopic differential diagnosis with alopecia areata*
}

\author{
Ana Cecília Versiani Duarte Pinto ${ }^{1}$ \\ Fernanda Freitas de Brito ${ }^{1}$ \\ Maria Lopes Lamenha Lins Cavalcante ${ }^{1}$
}

\author{
Tatiana Cristina Pedro Cordeiro de Andrade ${ }^{1}$ \\ Gardênia Viana da Silva ${ }^{1}$ \\ Antonio Carlos Ceribelli Martelli ${ }^{1}$
}

DOI: http:/ / dx.doi.org/10.1590/abd1806-4841.20175136

\begin{abstract}
Trichotillomania is a psychodermatologic disorder characterized by uncontrollable urge to pull one's own hair. Differential diagnoses include the most common forms of alopecia such as alopecia areata. It is usually associated with depression and obsessive-compulsive disorder. Trichotillomania treatment standardization is a gap in the medical literature. Recent studies demonstrated the efficacy of $\mathrm{N}$-acetylcysteine (a glutamate modulator) for the treatment of the disease. We report the clinical case of a 12-year-old female patient who received the initial diagnosis of alopecia areata, but presented with clinical and dermoscopic features of trichotillomania. She was treated with the combination of psychotropic drugs and N-acetylcysteine with good clinical response. Due to the chronic and recurring nature of trichotillomania, more studies need to be conducted for the establishment of a formal treatment algorithm.
\end{abstract}

Keywords: Alopecia; Dermoscopy; Trichotillomania

\section{INTRODUCTION}

Trichotillomania (TTM) is characterized - according to the Diagnostic and Statistical Manual of Mental Disorders (DSM IV) by persistent hair pulling behavior, resulting in noticeable hair loss. Patients report feeling anxious before pulling their hair out and pleasure, satisfaction, or relief after doing it. The disturbance is not accounted for by another mental disorder and is not due to a general medical condition. It causes significant distress or impairment in social, occupational, or other important areas of functioning. ${ }^{1} \mathrm{Clin}$ ical studies suggest that the prevalence of TTM varies from $0.6 \%$ to $3 \%$ and is more common in female patients. ${ }^{2}$ Differential diagnoses include more common alopecias such as alopecia areata (AA). TTM may be associated with depression, bipolar disorder, and obsessive-compulsive disorder. ${ }^{2,3}$ These associations, combined with the poor knowledge regarding the diagnosis and course of the disease, make treatment more difficult, which is still considered a challenge by the lack of systematization in the literature. We report a case of TTM that was initially diagnosed as AA. Our goal is to highlight the importance of clinical and dermatoscopic differential diagnosis between these two entities, as well as to exemplify our TTM patient's good response to treatment.

\section{CASE REPORT}

A 12-year-old female patient, accompanied by her mother, reported hair loss for the past six months after a family conflict. She had been previously diagnosed with AA and started topical treatment with minoxidil and clobetasol without improvement. The mother noted that, when the patient was nervous, she had an uncontrollable urge to manipulate the scalp, which intensified hair loss confirmed by the accumulation of hair around her. Dermatological examination revealed diffuse thinning with short, jagged, and broken hairs, and negative tensile test (Figure 1). At dermoscopy, we noticed different hair lengths with broken shafts, vellus hair, V-sign or ballerina baldness aspect, and numerous black spots. We observed no exclamation point hairs, nor yellow dots (Figure 2). The patient refused to biopsy of the scalp. We established a clinical and dermatoscopic diagnosis of TTM and began treatment with doxepin (10 mg/daily), fluoxetine (20 mg/daily), pimozide ( $2 \mathrm{mg} /$ daily), and $\mathrm{N}$-acetylcysteine (600 mg/every 8 hours). In addition, the patient was referred for psychological evaluation. She showed progressive improvement in the 6-month follow-up, with noticeable increase in capillary density and improved TTM dermoscopy findings (Figures 3 and 4). 

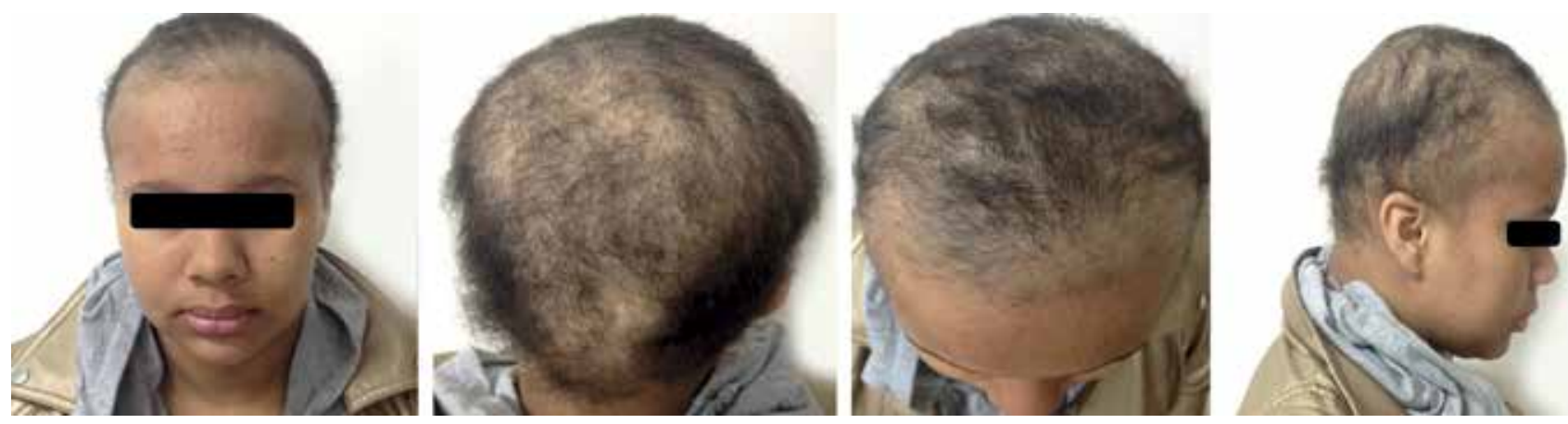

Figure 1: In the first consultation, we observed diffuse and irregular hair thinning with short hairs

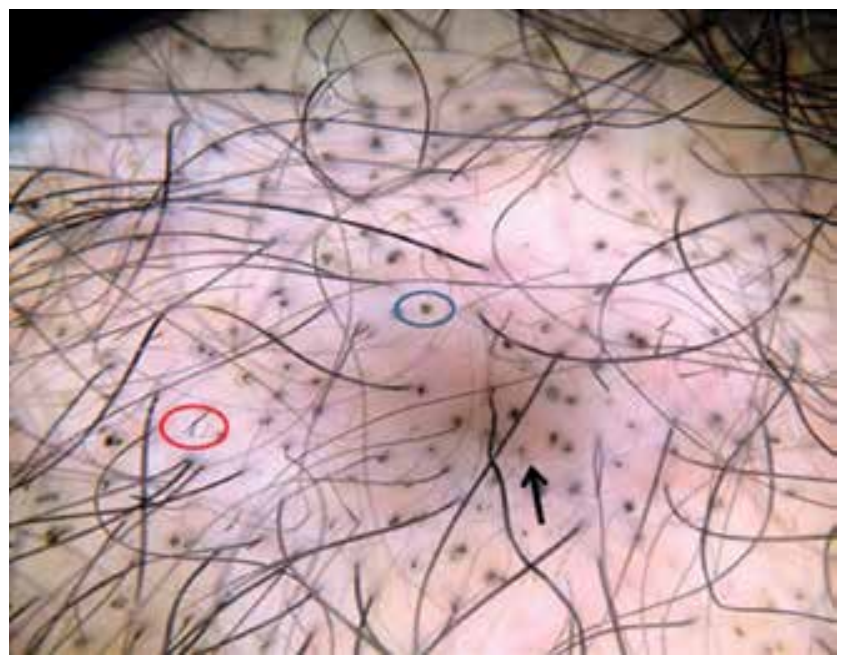

Figure 2: Dermoscopy revealed broken hairs of different lengths, vellus hair (black arrow), V-sign or ballerina baldness aspect (red circle), and numerous black dots (blue circle). Alopecia areata features - such as exclamation point hairs and yellow dots - were not observed
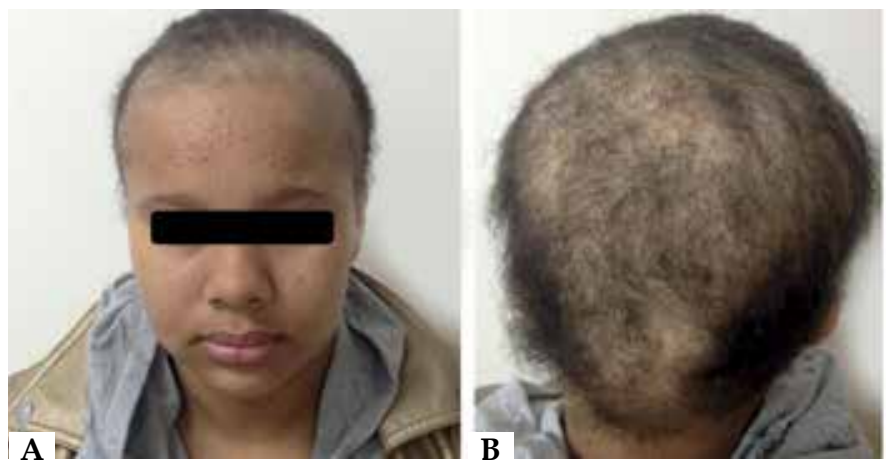

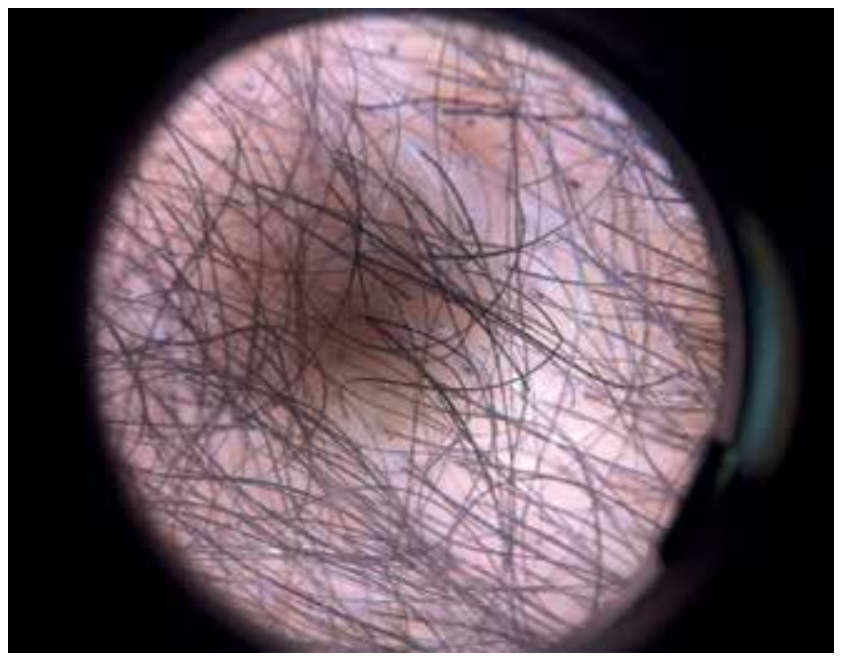

Figure 4: Dermoscopy showed an increase in capillary density, improvement of trichotillomania findings and hairs in the growth phase

Figure 3: We observed progressive improvement in the six months follow-up, with noticeable increase in capillary density. Compare figures $\mathrm{A}$ and $\mathrm{B}$ (before treatment) to figures $\mathrm{C}$ and $\mathrm{D}$ (after sixth months of treatment)

\section{DISCUSSION}

TTM was first described in 1889 by Hallopeau. It is currently ranked among the habit and impulse control disorders. ${ }^{2,3}$ Age at TTM onset varies from 9-13 years, and is more common in females, epidemiological characteristics consistent with our patient's. The main differential diagnosis of TTM is AA, which affects the same gender and age group and sometimes have very similar clinical features. Classical pictures of AA reveal smooth and shiny alope- cia patches with ragged edges due to traction. ${ }^{4}$ TTM, in its turn, reveals multifocal and irregular alopecia patches formed by multiple broken hairs with negative traction. Some reports, however, associate the two diseases, which poses a diagnostic challenge to clinicians. ${ }^{5,6}$ In this scenario, dermoscopy has emerged as a noninvasive and useful tool in the diagnosis of the disease. ${ }^{4,7}$ Indicatives of TTM findings include black dots, coiled hairs, shafts of various 
lengths, broom fibers, and V-sign (trichoptilosis). Exclamation point hairs, which are suggestive of AA, are commonly absent. ${ }^{4}$ Therapy for TTM still lacks scientific evidence and is based on case reports. ${ }^{7-9}$ Some strategies used include psychotherapy, behavioral therapy, and drugs - such as lithium salts, tricyclic antidepressants (TADs), selective serotonin reuptake inhibitors (SSRIs), and antipsychotics. Recently, $\mathrm{N}$-acetylcysteine has been proposed as an effective alternative treatment $t^{3,9,10}$ since the drug restores the extracellular glutamate concentration in the nucleus accumbens (low levels of extracellular glutamate concentration have been held responsible for the pathogenesis of compulsive behaviors, including the TTM) ${ }^{10}$ In a randomized, double-blind clinical trial comparing $\mathrm{N}$-acetylcysteine with placebo at doses ranging from $1.200 \mathrm{mg} /$ daily to $2400 \mathrm{mg} /$ daily, it was observed that $\mathrm{N}$-acetylcysteine was more effective and safer. ${ }^{10}$ It is noteworthy that, due to the chronic and relapsing nature of TTM, more studies need to be conducted in order to establish a formal treatment algorithm. We conclude that differential diagnosis between AA and MTA - two diseases affecting similar clinical profiles with potential stigmatising implications - is key to establish the correct therapeutic approach for each of the conditions.]

\section{REFERENCES}

1. American Psychiatric Association. DSM-IV: Manual diagnóstico e estatístico de transtornos mentais. 4. ed. Porto Alegre: Artmed; 2002.

2. Toledo EL, Taragano R, Cordás TA, Abreu CN, Hearst N, Conti MA. Adaptação transcultural da Massachusetts General Hospital (MGH) Hairpulling Scale para 0 idioma português (Brasil). Rev Psiq Clín. 2011;38:178-83.

3. Tirado MIM. Tratamiento cognitivo-conductual en una adolescente con tricotilomania. Revista de Psicología Clínica con Niños y Adolescentes. 2015;2:917.

4. Abraham LS, Torres FN, Azulay-Abulafia L. Pistas dermatoscópicas para diferenciar a tricotilomania da alopecia areata em placa. An Bras Dermatol. 2010;85:723-6

5. Ise M, Amagai M, Ohyama M. Follicular microhemorrhage: A unique dermoscopic sign for the detection of coexisting trichotillomania in alopecia areata. J Dermatol. 2014;41:518-20.

6. Shelleh HH, Khan SA, Al-Hatiti HS. Trichotillomania or alopecia areata ? Int J Dermatol. 2006;45:1196-8.

7. Lee DY, Lee JH, Yang JM, Lee ES. The use of dermoscopy for the diagnosis of trichotillomania. J Eur Acad Dermatol Venereol. 2009;23:731-2.

8. Sachdeva A. Managing a case of trichotillomania with trichobezoar. Int $\mathrm{J}$ Trichology. 2013;5:228-30.

9. Dougherty DD, Loh R, Jenike MA, Keuthen NJ. Single modality versus dual modality treatment for trichotillomania: Sertraline, behavioral therapy, or both? J Clin Psychiatry. 2006:67:1086-92.

10. Rodrigues-Barata AR, Tosti A, Rodríguez-Pichardo A, Camacho-Martínez F. $\mathrm{N}$-acetylcysteine in the Treatment of Trichotillomania. Int J Trichology. 2012;4:176-8.
MAILING ADDRESS:

Tatiana Cristina Pedro Cordeiro de Andrade

Rodovia Comandante João Ribeiro de Barros, quilômetros $225 / 226$

17034-971 Bauru, SP

Brazil

E-mail: tatianap.andrade@gmail.com

How to cite this article: Pinto ACVD, Andrade TCPC, Brito FF, Silva GV, Cavalcante MLLL, Martelli ACC. Trichotillomania: a case report with clinical differential diagnosis and dermatoscopic with alopecia areata. An Bras Dermatol. 2017;92(1):118-20. 